\title{
Acquisitions in the third party tracking industry: competition and data protection aspects
}

Reuben Binns, Postdoctoral Researcher, Department of Computer Science, University of Oxford.

Elettra Bietti, SJD, Harvard Law School.

\section{Introduction}

Amid growing concern about the use and abuse of personal data over the last decade, there is an emerging suggestion that regulators may need to turn their attention towards the concentrations of power deriving from large-scale data accumulation. No longer the preserve of privacy and data protection law, personal data is receiving attention within competition and antitrust law. Recent mergers and acquisitions between large digital technology platforms have raised important questions about how these different areas intersect and how they can complement one another in order to protect consumer welfare while ensuring competitive markets. The picture is complicated by the complex nature and structure of certain data-intensive markets, which are often multi-sided, fast-growing, characterised by network effects, and awash with venture capital which obscures long term business models in ways that defy short-term market definition. As Ariel Ezrachi and Maurice Stucke have expressed it, digital markets give rise to "an interesting atypical form of competition,"1 where companies simultaneously compete and collaborate, through a dynamic characterised by complex interlocking and conglomerate anticompetitive effects which they describe using the existing term "Frenemies".

This paper draws attention to one particularly complicated kind of digital dataintensive industry; that of third party tracking, in which a firm does not (only or primarily) collect and process personal data of its own customers or users, but rather of the users of other 'first party' services. For instance, the online advertising network DoubleClick provides ad serving and tracking technology which first party services can embed in their websites, which allows Doubleclick to profile users and target advertisements to them. The business models of third party tracking

\footnotetext{
${ }^{1}$ Ariel Ezrachi and Maurice Stucke, Virtual Competition, The Promise and Perils of the Algorithm-Driven Economy (2016), at 147.

${ }^{2}$ Id. supra, at 147 and following.
} 
vary, but often include the profiling of users for targeted advertising and extracting insights from their behaviour for analytics. We focus on mergers and acquisitions of third-party tracking firms because they raise some unique challenges which are often missed in regulatory decisions and academic discussions of data and market concentration.

Combining an empirical methodology with a critical assessment of some of the existing case law on these issues in the US and EU, we argue that a bolder approach is needed; one that engages in a pluralist analysis of economic and noneconomic concerns about concentrations of power and control over data.

Section 1 comprises a brief overview of the technical elements of third party tracking and of the business practices associated with it, and includes a discussion of some of the ways that antitrust authorities have been characterising these activities.

Section 2 presents an analysis of consolidations amongst third party trackers on 5,000 of the most popular websites and mobile applications. We identified a subset of acquisitions between third party tracking firms which are most significant in terms of the data sources being merged as a result.

Relying on this dataset, section 3 highlights why it may be important to consider the specific kinds and sources of first party data that each of the third parties involved in a consolidation has access to, for both competitive market and privacy reasons. In section 4, we turn to analysing the practice of the European Commission and the US Federal Trade Commission in relation to mergers in the third party tracking sector, assessing the extent to which these competition authorities' practices reflect the significance of the data-mergers identified in section 2 . We note three things. First, that only a proportion of cases which we consider significant are in fact reviewed by competition authorities. Second, that amongst the transactions that have in fact been scrutinized from a competition law perspective, only a small proportion are examined in depth. Third, after an analysis of this latter subset of decisions, we argue that competition authorities' approach largely disregards privacy impacts, and focuses on first party aspects, more or less consciously eliding the substantial third party tracking issues that arise.

Section 5 presents two competing paradigmatic views of the role and scope of competition / antitrust law enforcement: the purist neoclassical view, according to which the privacy impacts of mergers are not within the scope of the antitrust analysis, and the pluralist view, according to which a plurality of values including privacy inform antitrust analysis. We then develop an understanding of how to value data in this context.

Finally, section 6 summarises and reflects on some of the unique challenges raised by consolidation in third party tracking markets for regulators. The way these are addressed depends on evolving institutional views about the relationship between competition and data protection. We thus argue in favour of a collaborative dialogue between competition and data protection authorities. 


\section{An overview of third party tracking}

This section provides an overview of what third party tracking is, and how antitrust and competition authorities have addressed it, if at all, in reviews of transactions between firms that engage in third party tracking.

\subsection{Third party tracking}

We use 'tracking' here to denote a range of data collection and processing practices which aim to collate the behaviours and attributes of end-users of digital technologies. It is commonly used to refer to technology which is embedded by a third party on multiple first party websites or mobile applications. Third parties create 'libraries' and 'software development kits' for mobile apps, or snippets of code which can be embedded in the html source of a website page. Typically, when a user installs the app, or views the website, the third party code collects data from the session and associates it with a (usually unique) identifier, which is sent to a remote server controlled by the third party. Since the same third party code is typically embedded on multiple different websites or apps, a single user's behaviour on multiple different apps / websites can be combined into a single behavioural profile, which might include session duration, content they viewed, or their geolocation data.

Third party tracking serves many different purposes. In some cases, they provide basic measurements for the first party, such as how an app or website is used, which pages are visited or when an error occurs. 'Audience measurement' and analytics services like Adobe Audience Manager go a little further, by matching website visitors to external information comprising their demographics and interests, and providing it back to the first party. Others provide varieties of functionality such as payment provision, authentication or security, and track users across services for these purposes. For instance, Distil Network's 'Are You a Human' service tracks users across multiple sites, monitoring their behaviour to distinguish human users from the automated activity of software agents or 'bots' (a kind of automated Turing test). This information is provided back to the first parties to help them automatically block bots from parts of the website or app.

Where the purpose is targeted advertising by marketers, behaviours that a user engages in on one website or app could feed into a profile which may lead to targeted advertisements being delivered on another website or app. For instance, viewing a pair of shoes on a fashion app or website might lead to the user seeing advertisements for the same product on a different app or website. Advertisers may pay the ad network per impression (i.e. the advert being displayed) or only if the user clicks, and the app developer / website owner will receive a portion of these revenues accrued by the ad network. While the provision of user data to ad networks is usually coupled with in-app or in-site display advertising, this is not 
always the case. In some cases, a third party might remunerate a developer / website owner for providing the data directly, rather than indirectly through targeted ad placements. Services like Fuse Data, MobKnow, and Tomoco allow app developers to get paid directly for provision of user data, without having to include advertisements in their apps. While such firms are often vague about who their customers are, the data they buy may end up being sold to ad networks in order to target ads to users when they use other apps which do run display advertising.

In many cases, third party trackers do not provide monetary benefits to first parties, but instead provide some useful free service - such as analytics, proprietary fonts, or social media sharing buttons - and use these integrations as a means to collect user data for some other commercial purpose. For instance, Google Analytics provides a free service to website operators to understand how their users use the website, but that user data is also used by Google for its targeted advertising businesses. Third parties like Doubleclick (also owned by Google / Alphabet), on the other hand, offer ad serving capabilities as a service.

The third party advertising technology ecosystem has evolved to encompass even more complex arrangements between multiple third parties. For instance, a user's behavioural profile might be comprised of data collected by more than one third party tracker. Some third parties specialise in matching online users to their offline profiles held by data brokers (e.g. LiveRamp, a subsidiary of the data broker Axciom). The placement of advertisements often works through automated auctions, where multiple advertisers are bidding for the same advertising opportunities in real time through an 'ad exchange' intermediary. Multiple ad networks might be embedded on the same app or website, allowing the first party to select whichever network offers the best remuneration for any given available space. In such cases, rather than integrating multiple different ad network's code into a single app or site, many developers rely on 'programmatic' ad network aggregators which handle multiple different networks and find the most profitable ads to serve in real-time. The amount that advertisers are willing to pay will depend on what kind of users the first party can serve ads to; and the more that the first and/or third party knows about users, the better they can target ads and the more they can charge the advertiser.

Recent studies of third party tracking on the web and mobile apps show that tracking is almost ubiquitous, and most first parties include code which allows their users to be tracked by multiple third parties. ${ }^{3}$ The kinds of data collected by third

\footnotetext{
${ }^{3}$ See e.g.:

Acar, G., Eubank, C., Englehardt, S., Juarez, M., Narayanan, A., \& Diaz, C. (2014, November). The web never forgets: Persistent tracking mechanisms in the wild. In Proceedings of the 2014 ACM SIGSAC Conference on Computer and Communications Security (pp. 674-689). ACM;

Yu, Z., Macbeth, S., Modi, K., \& Pujol, J. M. (2016, April). Tracking the trackers. In Proceedings of the 25th International Conference on World Wide Web (pp. 121-132). International World Wide Web Conferences Steering Committee;
} 
parties varies between devices, platforms, genre of app / website, and purpose of tracking. At a minimum, third parties assign and / or record a unique identifier which allows an interaction to be associated with the user. Web browser information, such as the version number, plugins installed, and fonts used, is also often captured as it is often uniquely identifying in combination. Common kinds of data collected via smartphone applications include location data (which can be highly accurate using GPS), a list of other applications installed, the type of handset, etc. Beyond this, a range of information pertinent to the application (e.g. stories interacted with on a news website) and the purposes of tracking might be collected.

\subsection{In what form have competition authorities examined third party tracking?}

The complexity and (often) lack of direct monetization of third party tracking activities has made them a much neglected aspect of digital markets for competition authorities. Competition authorities have tended to focus on specific "purposes" of third party tracking that constitute distinct "markets", such as marketing information services or the sale of online advertising, rather than on the versatile third party tracking activities themselves, such as data collection, the training of complex machine learning models or the compilation of digital profiles. Authorities have focused on money flows rather than data flows, and on individuals as direct paying customers, rather than as remote third parties affected by a company's tracking activities while having no contractual relationship with the company itself.

Under EU law, a "market" "comprises all those products and/or services which are regarded as interchangeable or substitutable by the consumer by reason of the products' characteristics, their prices and their intended use". ${ }^{4}$ In other words, a market constitutes a sector of activity characterised by a set of uniform characteristics which apply to all firms active in it, and which makes these firms' respective actions in that particular sector of activity interdependent. In light of their focus on "customers" and on money flows, the European Commission has been distinguishing at least two separate sectors of activity with broad overlaps with third party tracking: online advertising activities and data analytics services.

Regarding data analytics services, in Case No COMP/M.2291 - VNU / AC NIELSEN ${ }^{5}$ and Case No COMP/M.6956 - TELEFONICA/ CAIXABANK/BANCO

\footnotetext{
Binns, R., Lyngs, U., Van Kleek, M., Zhao, J., Libert, T., \& Shadbolt, N. (2018, May). Third Party Tracking in the Mobile Ecosystem. In Proceedings of the 10th ACM Conference on Web Science (pp. 23-31). ACM;

Binns, R., Zhao, J., Van Kleek, M., \& Shadbolt, N. (2018). Measuring third party tracker power across web and mobile. ACM Transactions on Internet Technology (TOIT),

Volume 18 Issue 4, September 2018 Issue-in-Progress, Article No. 52.

${ }^{4}$ Commission Notice on the definition of relevant market for the purposes of Community competition law, OJ C 372, 9.12.1997, at para. 7.

${ }^{5}$ Commission decision of 12 February 2001 in Case COMP/M.2291 - VNU / ACNielsen.
} 
SANTANDER/JV, ${ }^{6}$ the Commission broadly distinguished market research services, that consist of reports on consumer attitudes and actual purchasing patterns, marketing information services, that entail the creation and supply of data profiles on individual consumers for direct marketing purposes, and media measurement services, which are aimed at measuring the audience of specific media, such as television and internet. In this and other decisions concerning data analytics activities, the Commission focused on the sale or licensing of data, without investigating the upstream activities that are inputs to data analytics, which often entail data collection through invasive third party tracking.

Regarding the online advertising market, the European Commission has been somewhat more specific. In its decision to clear the Google/DoubleClick merger in $2008,{ }^{7}$ the European Commission provided an overview of the functioning of online advertising services markets, determining that online and offline advertising services constituted two separate markets, ${ }^{8}$ and exploring further segmentations of online markets, including the distinction between search and non-search online advertising, ${ }^{9}$ and that between direct and intermediated sales of online advertising. In a similar fashion to the US Federal Trade Commission (FTC) in its decision on the same merger, ${ }^{10}$ the Commission distinguished a number of possible forms of online advertising "intermediation". The Commission describes three categories of intermediaries: "ad networks," "ad exchanges" and "media agencies."11 $\underline{\mathrm{Ad}}$

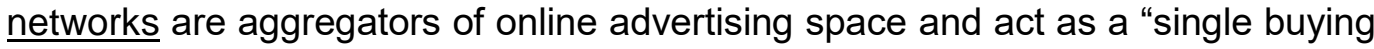
point" for advertisers. ${ }^{12}$ Ad exchanges are instead auctions or marketplaces where advertisers and publishers can virtually meet and directly buy or sell ad space in real-time. ${ }^{13}$ Finally media agencies buy aggregated advertising space for advertisers, who are their direct customers. Media agencies also operate through ad networks and ad exchanges. In addition, the Commission and the FTC both considered the market for ad serving tools, on which Doubleclick was active, which includes tools for generating, displaying, serving and measuring the reach of ads, ${ }^{14}$ an activity closely associated with third party tracking. The Commission in 2008 premonitorily highlighted a trend towards vertical integration of intermediaries with ad serving providers. ${ }^{15}$ In other cases, the European Commission suggested a possible distinction between online and mobile advertising ${ }^{16}$ and also considered

\footnotetext{
${ }^{6}$ Commission decision of 14 August 2013 Case No COMP/M.6956 - TELEFONICA/ CAIXABANK/BANCO SANTANDER/JV.

${ }^{7}$ Case COMP M.4731, decision of 11 March 2008, http://ec.europa.eu/competition/mergers/cases/decisions/m4731 2008031120682 en.pdf.

${ }^{8}$ For several reasons including the capacity of online advertising of being targeted at users, its capacity to let advertisers to know at a very high level of precision how many users have viewed or clicked on an ad, and also that pricing mechanisms are very different for online and offline advertising

9 Id. at para 56.

10 Statement of the Federal Trade Commission Concerning Google/DoubleClick of 20 December 2007.

${ }^{11}$ Id. supra note 9 , at para 20.

12 Id. at para 20.

13 Id. at para 21.

14 Id. at section 6.1.3. (add ref to FTC)

15 Id. at para 32 and following.

${ }^{16}$ M.6314 Telefónica UK / Vodafone UK / Everything Everywhere / JV, decision of 6 February 2013,
} 
the possibility that advertising on different platforms such as PCs or mobile phones constitute separate markets. ${ }^{17}$ It does not seem to have ever analysed specifically whether tracking for advertising purposes may have distinct characteristics on mobile or on the web .

Overall, the focus of competition authorities on "markets" as directly monetizable sectors of activity has led to their gravitation towards areas where data is sold for a direct profit such as data analytics services and the sale of advertising space and to their neglect of important challenges relating to the market power of certain entities whose third party tracking activities include data collection, sharing and profiling.

"Third party tracking" does not appear to have ever been mentioned as such in competition authority decisions. As noted above, in both of their decisions regarding the Google/Doubleclick merger, the European Commission and the FTC refer to "third party ad serving" as the tools which enable the delivery and tracking of online advertisements, a market on which, at the time of the merger, Doubleclick was an active and predominant player. ${ }^{18}$ The FTC dwells on some of the data aspects of ad serving technology, while maintaining a focus on its instrumentality to the sale of advertising space:

"Advertiser side ad servers also provide key data that is used to plan, manage, maintain, track, and analyze the results of online campaigns across multiple publisher websites. Like publishers, advertisers pay for the use of ad serving services on a cost per thousand ads served."19

In Microsoft/Linkedln ${ }^{20}$ as discussed below, the European Commission analysed some of the merger's data aspects. However, it described Microsoft and Linkedln's relevant datasets excessively narrowly, including only the data collected from their respective customers, not the data these companies collect as third parties on other sites or apps:

"Linkedln full data refers to all the data that Linkedln collects, or could collect, and store about its users and their activity, such as professional details, connections, interests, posts, endorsements." 21

"[T]he Transaction does not raise competition concerns resulting from the possible post-merger combination of the "data" (essentially consisting of personal information, such as information about an individual's job, career history and professional connections, and/or her or his email or other contacts,

\footnotetext{
http://ec.europa.eu/competition/mergers/cases/decisions/m63142012090420682 2898627 EN.pdf.

${ }^{17}$ European Commission Case COMP M.7217 FACEBOOK/ WHATSAPP (3 October 2014), http://ec.europa.eu/competition/mergers/cases/decisions/m721720141003203103962132 EN.pdf.

${ }^{18}$ European Commission Case COMP/M.4731 GOOGLE / DOUBLECLICK (11 March 2008); Statement of the Federal Trade Commission Concerning Google/DoubleClick of 20 December 2007.

${ }^{19}$ FTC statement, at p. 6.

${ }^{20}$ Commission Decision of 6 December 2016 Case M.8124 - Microsoft / Linkedln

${ }^{21}$ Id. supra, at p. 12.
} 
search behaviour etc. about the users of their services) held by each of the Parties in relation to online advertising."22 (Emphasis added.)

It should be noted that while the definition appears to neglect a large portion of Microsoft and Linkedln's third party tracking activities, it could nonetheless encompass some data collection from third party sites about their own customers, eg. collected through the use of APIs. This ambiguity is regrettable, since it is not clear whether the Commission would have been fully aware of the extent to which both firms were capable of tracking individuals outside of the Microsoft and Linkedin services, on a range of websites and apps which used their third party services. Still, as we will see below, these definitions illustrate an endemic propensity to focus on first party activities and to overlook third party tracking.

\section{Empirical investigation of data- combination resulting from third party tracker consolidation}

Third party trackers have commercial advantages over first parties; not only do they create efficiencies of scale by developing and maintaining tracking software, they can also aggregate data from multiple first party services to produce richer profiles of individuals. This is because they can access a richer pool of data and are not constrained by contractual data privacy policies which can arguably limit their data processing activities. By contrast, a first party website or app only has access to the data of its own users as they engage with that particular service. This makes the data less valuable as less is known about any given user. The reach of a third party tracker is important whether its purpose is ad targeting, analytics, or direct data monetisation. Even the value of a security-oriented service like the bot-detection tracker discussed above is a function of its distribution across multiple first parties, because its bot-detection algorithm will be more accurate with more behavioural data on more users from a variety of sources. In each case, the extent to which it is integrated into a large number of first parties, and the popularity of those third parties with users, is one of the key factors in the power, and hence potential profitability, of a third party tracker.

In previous work, these aspects of third party tracker power have been discussed in terms of prevalence - defined as the number of first parties on which a third party tracker is present - and prominence - where such prevalence is weighted by the number of users of the first parties. ${ }^{23}$ Prevalence and prominence are both important; a tracker with high prevalence has the opportunity to combine user data

\footnotetext{
22 Id. supra, at p. 34.

${ }^{23}$ Binns, Reuben, et al. "Measuring third party tracker power across web and mobile." arXiv preprint arXiv:1802.02507 (2018).

Binns, R., Lyngs, U., Van Kleek, M., Zhao, J., Libert, T., \& Shadbolt, N. (2018). Third

Party Tracking in the Mobile Ecosystem. arXiv preprint arXiv:1804.03603.
} 
from multiple different first parties, but if those first parties have very few users (i.e. low combined prominence) the data is unlikely to be so valuable. Conversely, a third party tracker which is present on a single very popular first party service will not have significantly more value than the first party itself; as such, it would have little value as an ad network, because advertisers or data brokers could deal directly with the first party instead.

Recent large-scale empirical studies have investigated the prevalence and prominence of third party trackers on websites and apps. ${ }^{24} \mathrm{~A}$ small number of companies dominate across both the web and mobile; these include technologies that are owned by Google or Google subsidiaries (in turn owned by Alphabet), Facebook, Twitter, Adobe, and others. Binns et al 2018 used measures of prevalence and prominence, for web and mobile (both separately and combined), in combination with standard indexes of market concentration (e.g. the Herfindhal Hirschman Index) to measure the extent of concentration amongst third party trackers. While these measures do not account for the type and sensitivity of data collected, they do provide a standardised and practical way of measuring the 'reach' of a given tracker. Such measures are useful if we want to understand the significance of a merger or acquisition involving one or more third party trackers, from the perspective of the data being combined and the power this brings.

This section presents an analysis of mergers and acquisitions involving third party trackers that are most significant from the perspective of data combination. We use the data from previous studies as a starting point, combined with external data on mergers and acquisitions, to identify the most significant data combinations resulting from transactions. We begin by describing the process of identifying and calculating the prevalence and prominence of third party trackers on the web and mobile platforms, undertaken in previous research. ${ }^{25}$

First, a sample of the most popular websites and mobile applications were identified. For the web, this was based on the 5,000 most visited websites according to the Alexa rankings. ${ }^{26}$ For mobile applications, this was based on the 5,000 most popular applications listed in the Google Play Store (where popularity is measured by number of downloads). ${ }^{27}$ Web trackers were identified using the OpenWPM web crawling tool, developed by researchers at Princeton, which detects the presence of third party trackers through analysis of network traffic generated during automated browsing sessions of the 5,000 websites. Mobile trackers were identified by downloading the 5,000 most popular Android applications, and applying an automated code analysis tool to detect the presence of third party code which included references to external host domains. Further

\footnotetext{
24 ibid

25 ibid

${ }^{26}$ Alexa.com.

${ }^{27}$ We were unable to perform this analysis on the Apple iPhone app store due to various technical and legal restrictions prohibiting on external analysis.
} 
details of methods for detection of third party trackers in both platforms can be found in the original paper detailing how the dataset was obtained and analysed. ${ }^{28}$

Having identified over 14,000 distinct web domains and code libraries amongst the web traffic and Android application code, we traced these to the specific companies who operate the services associated with them. We removed any domains and third party code libraries which did not appear to be facilitating tracking (based on both network traffic analysis and publicly available documentation). Having traced code libraries and domains to specific companies, we also compiled supplementary information about the company's primary business, and whether it had any parent / subsidiary relationships with other companies.

This allowed us to measure the prevalence and prominence of third party trackers on the 5,000 most popular websites and (Android) mobile apps. For instance, the third party tracker with the highest prevalence among first-party services, across both web and mobile, is the analytics service Google Analytics. In second place is Doubleclick, a behavioural advertising network. Google bought Doubleclick in 2008, and in combination with other trackers under the Google family, it now has a combined prevalence of over $70 \%$ of websites and over $80 \%$ of all mobile applications.

As some of the cases discussed below show, consolidation between third party trackers has the potential to result in the merging of personal data from multiple sources into a single profile. While not every consolidation will necessarily result in data-merging, it seems likely that this will be the norm; even in cases where acquiring firms promise to maintain separation between data sources, such promises may be broken or circumvented, as in the case of Facebook / Whatsapp..$^{29}$ The dataset presented here allows us to examine the extent to which consolidations raise the prevalence and prominence of a given firm, assuming that a merger or acquisition does indeed result in data combination in the resulting merged firm.

We thus began by cross-referencing any market consolidations involving any of the third party trackers in the dataset. These were compiled from public sources including public registers of company ownership, ${ }^{30}$ and the technology industry monitoring site like CrunchBase. ${ }^{31}$ Using the existing data on the prominence of each party, we ranked the transactions in order of the largest combined prominence. This represents the magnitude of the data-combination involved in the merger or acquisition.

\footnotetext{
${ }^{28} \mathrm{lbid}$, section 5.

${ }^{29} \mathrm{https}$ ://uk.reuters.com/article/uk-eu-dataprotection-whatsapp/facebooks-eu-regulatorsays-whatsapp-yet-to-resolve-data-sharing-issue-idUKKCN1GC2HA

${ }^{30}$ www.opencorporates.com

${ }^{31}$ www.crunchbase.com
} 
It is important to note a limitation of this method; the data represents the distribution of third parties on websites and apps at a single point in time (the data collection period spanned over November 2016-January 2017). Ideally, we would measure the prominence of the parties involved immediately prior to the acquisition, to get the most accurate picture of each party's reach at that point in time. But in practice, acquisitions and mergers occurred before and after the data collection period and in the intervening time the picture may have changed. For instance, we cannot know how the distribution of e.g. DoubleClick might have differed in the time between 2008 and 2018, if it hadn't been acquired by Google. Thus, when we discuss the data-combination associated with Google / Doubleclick, it is on the basis of the current distributions of the third party technology associated with each firm (which likely differed at the time of acquisition in 2008). However, unlike the Google / Doubleclick case, the majority of the transactions in question occurred within 2 years of the time of data collection. Another limitation is that we focus on samples of first parties (5,000 websites and 5,000 Android apps), rather than the entire web or Android app store or a smaller subset of the most popular websites; different samples would likely result in (small) changes in the significance of each consolidation.

The table below shows acquisitions between third party tracking firms in order of the largest increases in prevalence for the parent firm after consolidation (the rank order for prominence is omitted for brevity, but similar). ${ }^{32}$

${ }^{32} 6$ acquisitions involved acquiring firms which previously had no presence in third party tracking; these have been omitted as, from a competition perspective they do not change the market concentration. 


\begin{tabular}{|c|c|c|}
\hline Target & Year & Acquirer \\
\hline Doubleclick & 2008 & Google \\
\hline Youtube & 2006 & Google \\
\hline Firebase & 2014 & Google \\
\hline Admob & 2009 & Google \\
\hline Linkedln & 2016 & Microsoft \\
\hline Liverail & 2014 & Facebook \\
\hline Crashlytics & 2013 & Twitter \\
\hline Bitstadium & 2014 & Microsoft \\
\hline Mopub & 2013 & Twitter \\
\hline Demdex & 2011 & Adobe Systems \\
\hline Tube Mogul & 2016 & Adobe Systems \\
\hline Livefyre & 2016 & Adobe Systems \\
\hline Umeng & 2013 & Alibaba \\
\hline Yahoo & 2017 & Verizon \\
\hline Radium One & 2017 & RhythmOne \\
\hline Addthis & 2016 & Oracle \\
\hline Aol & 2017 & Verizon \\
\hline Instagram & 2012 & Facebook \\
\hline Moat & 2017 & Oracle \\
\hline Flurry & 2014 & Verizon \\
\hline Brightroll & 2017 & Verizon \\
\hline Adcolony & 2014 & Opera \\
\hline Flickr & 2017 & Verizon \\
\hline Tumblr & 2017 & Verizon \\
\hline Maxymiser & 2015 & Oracle \\
\hline aerserv & 2018 & inmobi \\
\hline Millenialmedia & 2017 & Verizon \\
\hline Typekit & 2011 & Adobe Systems \\
\hline Bluekai & 2014 & Oracle \\
\hline Krux & 2016 & Salesforce \\
\hline One By Aol & 2017 & Verizon \\
\hline
\end{tabular}

These transactions represent the most significant combinations of first party data resulting from third party consolidation. While there are many other firms engaged in third party tracking, and a number of other mergers and acquisitions involving them, they are not included here; either because none of them involved more than 5 first party websites / mobile apps $(0.001 \%$ of the apps / sites in the sample), or 
because they acquired / were acquired by a company which itself had no significant third party presence. 42 acquisitions met this criteria (the 10 smallest are excluded from the table for brevity).

\section{How the nature of first party data sources involved in third party mergers could affect competition and privacy}

By identifying the most significant third parties from a large representative sample of first parties, and then identifying any of those which are involved in mergers or acquisitions, our approach emphasises the significance of third party data sources being combined, rather than the size (e.g. in market cap or revenue share) of the firms in question. This third party-oriented approach helps surface issues that might otherwise be missed in competition and antitrust analysis. In particular, this section illustrates why a focus on the nature of the first party data being combined by third parties might be important, by picking a few instances from the dataset discussed above. Some third party trackers may be skewed towards integration with certain categories of sites and apps, so the specific combination of different data sources as a result of a merger between two third party trackers could have important effects on both the economic position of the parties and on consumer privacy.

First, the specific combinations of data sources that a third party tracker has access to might significantly determine their commercial opportunities, ie. their position and power on the market(s) that they are active in or their ability to access neighbouring markets, as well as the kinds of services they can provide and the value of their data post-transaction. For instance, an ad network which is prevalent on social networks might significantly increase the value of its targeting by acquiring a target which is prevalent on dating apps, if the value of social network data to ad targeting in the context of dating is high (or vice-versa). Similar combinations were involved in the case of AOL's acquisition of Flurry; Flurry tracks 5 million users the social network app TimeHop, which became combined with AOL's existing tracking of users of dating apps like TopFace and Queep (10 million users each). Likewise, the ability to identify visitors to a property search website might be much more valuable if one also has the ability to identify the same users in a finance app in which people are likely to click on mortgage adverts. This may be the case for Krux, present on property search site iScout (5 million users), which was acquired by Salesforce which is present on the German finance advice site Finanzen.net. Such examples suggest that the kinds of sites a third party tracker has access to - whether in terms of the kinds of user data it has access to, or ability to place ads - may determine the kinds of advertising clients they attract and the value of their services. Since mergers and acquisitions affect the kinds of sites a 
third party tracker has access to, in this way they could have important effects on market competition that might be of interest to competition regulators.

Interestingly, consideration of the different types of data collected by the merging entities and consequences for post-merger competitiveness were in fact raised in the European Google/Doubleclick merger decision. The Commission noted that the types of data that would be combined as a result of the merger could potentially impact competition:

"Competition based on the quality of collected data ... is not only decided by virtue of the sheer size of the respective databases, but also determined by the different types of data the competitors have access to and the question which type eventually will prove to be the most useful for internet advertising purposes." 33

However, the specific kinds and sources of first party data collected by Doubleclick, and how they might interact with the kinds and sources of data already collected by Google, was not discussed further in this case. And such consideration of the nuances of different first party data sources being combined did not appear in any of the other reviews we analysed.

Second, the particular combinations of first party data are also important from a privacy perspective, because if the acquisition results in user data from two different services being merged into a single user profile, new privacy risks may arise. Pre-acquisition, an individual might have a profile at company $A$ which contains their browsing habits on news websites, and another profile at company $B$ which contains their medical search history from health websites. Postacquisition, these profiles from $A$ and $B$ may be merged into a single profile linking information contained in both. Now, the individual's news media interests can be correlated with their health condition; their medical searches might feed into a targeted advertisement that appears when they read the news.

This example could describe Adobe's acquisition of Tubemogul, for instance, in 2016. Tubemogul is an ad network which tracks the activity of visitors to various websites, including the health website MensHealth.com; after acquisition by Adobe, such data would likely have been integrated into the profiles contained in Adobe's existing ad technology platform which is present on $10 \%$ of the most popular websites, including many of the largest news, travel and retail services. For users of the health website, a significant change will have occurred in terms of the richness and sensitivity of the data contained within those profiles. They may find that the symptoms they entered into a health website result in a display advertisement for particular medications or treatments as they read the news, a privacy violation which would not have been possible without that particular acquisition.

Examples like these show that the significance of a merger between third party entities may crucially depend on the specific kinds of data sources being

${ }^{33}$ European Commission decision of 22 July 2008 M.4731 Google/Doublelick, at para. 273. See also para 360. 
combined. This section has shown that competition and data protection considerations are much closer and more interrelated than one initially could have envisaged, when it comes to the merger of two separate entities' databases. The next section will expand this argument, by examining competition authorities' approaches in greater depth. As we will see, competition authorities have largely glossed over questions of how of the types of data being merged can contribute to an increase in control and economic power. But our argument goes further: no matter the types of datasets being merged, the question of how these affect the merging parties' economic position does not seem to have been addressed head on by any of the authorities whose decisions we examined.

\section{Competition law analysis of data- significant transactions}

After identifying the 42 relevant M\&A transactions through the approach described in section 2, we then searched for each transaction in the databases of five competition authorities, to determine whether the transactions have been scrutinized from a competition law perspective: the US Federal Trade Commission, ${ }^{34}$ the European Commission, ${ }^{35}$ the UK Consumer Markets Authority $(\mathrm{CMA}),{ }^{36}$ the French antitrust authority ${ }^{37}$ and the Italian Autorità Garante della Concorrenza e del Mercato (AGCM). ${ }^{38}$

We noted that out of the 42 decisions, only 21 were scrutinized by one or more of the five competition authorities which we focused on. We found no decisions by the French and Italian authorities, in spite of one of the companies being involved in a few significant transactions, Criteo, being French. We found one decision by the UK CMA's predecessor, the Office of Fair Trading. Most of the decisions we found were summary clearances, and only five of the 42 transactions were the subject of in-depth competition law investigations by one or more of these authorities: seven full-merits decisions in total. ${ }^{39}$ In only four of these seven decisions, competition/antitrust authorities actually explored the overlaps of competition and data protection law when it comes to the merger of different entities' datasets, and in all four they appear to dismiss those issues. ${ }^{40}$

\footnotetext{
${ }^{34}$ https://www.ftc.gov/enforcement/merger-review 35

http://ec.europa.eu/competition/elojade/isef/index.cfm?fuseaction=dsp merger ongoing

${ }^{36}$ https://www.gov.uk/cma-cases

${ }^{37} \mathrm{http://www.autoritedelaconcurrence.fr/user/tableaudcc.php}$

${ }^{38}$ http://www.agcm.it/en/search.html

39 Google/DoubleClick (EC and FTC), Google Inc./AdMob (FTC), Microsoft/Linkedin (EC), Verizon/Yahoo (EC), Facebook/Instagram (FTC and UK OFT/CMA).

40 Proposed Acquisition of Hellman \& Friedman Capital Partners V, LP, (Click Holding

Company) By Google Inc. (20 December 2007), Case COMP/M.4731 - Google/
} 
For thoroughness, we also checked the databases to see if any of the companies involved in those mergers were also involved in other transactions which were reviewed in depth by these five competition authorities in spite of not leading to an actual merger. We found one such transaction: Microsoft's acquisition of Yahoo Search. The European Commission and the US Federal Trade Commission cleared it, ${ }^{41}$ but the acquisition never went through. ${ }^{42}$ Had it happened, it would no doubt have been included on our shortlist. Thus, we decided to include the European Commission's competition law review of this transaction in our analysis.

Our analysis thus focused on the four clearance decisions identified as per above and on the European Commission's decision in Microsoft/Yahoo.

\subsection{Microsoft/Yahoo}

We decided to include this case because according to our study the transaction which did not go through - had the potential to significantly impact individuals subject to third party tracking. What we found is a patent failure of the European Commission in this case to acknowledge the harms at stake. ${ }^{43}$

In the decision, the European Commission mentioned the third party trackingrelated aspects of online advertising a number of times. The Commission for instance described behavioural targeting across the web, using the term "user behaviour" which eludes the question of whether the targeting concerns individuals who are not users of the relevant first party service:

"A growing number of both search and non-search ads are also behaviourally targeted. That means that in addition to other targeting criteria ... the ads to be served are selected according to the individual's previous web-browsing behavior. Information on that user behaviour is collected by using so-called "cookies"."44

In the decision, the Commission also referred to APIs as "syndication agreements" which enable "third party publishers to use a search engine's technology and an ad platform's pool of ads to deploy internet search services and search ads ... onto their websites." 45

DoubleClick (11 March 2008), Case COMP/M.8124 - Microsoft / Linkedln (6 December 2016), Case COMP/M.8180 - Verizon / Yahoo (21 December 2016).

${ }^{41}$ Case No COMP/M.5727 - MICROSOFT/ YAHOO! SEARCH BUSINESS (18 February 2010), The US FTC cleared the merger on 17 February 2010:

https://www.ftc.gov/enforcement/premerger-notification-program/early-terminationnotices/20090650.

${ }^{42}$ See some of the history here: https://searchengineland.com/library/features/microsoftyahoo-merger.

${ }^{43}$ European Commission Case No COMP/M.5727 - MICROSOFT/ YAHOO! SEARCH BUSINESS (18 February 2010).

44 Id. supra, at para 40.

$45 \mathrm{Id}$. supra, at para 51-52. 
Most interesting however is the Commission's treatment of the possible anticompetitive harms at stake. The transaction would have entailed the merger of the second and third largest search engines in the EEA, and thus could have led to the creation of a very large combined database on individual search users. Yet the Commission did not mention at all the potential risks from a privacy perspective, nor the question of whether the quality of search could be affected negatively by an increase in the potential of all parties in the ecosystem to harvest data. Instead, the Commission limited its analysis to the potential price and quality benefits that the merger would bring about.

When examining the effects of the merger on advertisers, publishers and distributors of advertising, the Commission recognized that these interested parties all welcomed the transaction as a positive constraint on Google's search dominance. ${ }^{46}$ This is not surprising in light of the fact that all of these stakeholders have an interest in accessing more personal data on more competitive terms: less concentration on the search market in this case meant more competitive access to such data and use of it in targeting ads. The Commission for example stated that: "it can be expected that the mere fact that adCenter and Bing will have to deal with much more traffic, and thus will have much more data available for experimentation, will tend to increase the quality of their product". ${ }^{47}$

However one would at least have expected that data-related harms would have been identified as part of the Commission's analysis of the merger's effect on internet search users, ie. individuals. Yet the Commission chose to focus on innovation, ie. the quality of organic search and the harm to users caused by a loss in variety, ${ }^{48}$ dramatically failing to mention any privacy concerns. At paragraph 223, the Commission even optimistically stated that:

"as submitted by the notifying party and as analysed above, the effects of scale are likely to allow the merged entity to run more tests and experiments on the algorithm in order to improve its relevance."49

In this decision, privacy harms are not only viewed as irrelevant to the competition analysis, they are overtly ignored. The Commission failed in two ways: it did not fulfill its obligation to protect individual interests and it unduly celebrated the competitive interests of data harvesters in the advertising ecosystem.

\subsection{Google/Doubleclick}

As mentioned above, the Google/Doubleclick merger generated two full merits reviews, one by the European Commission and one by the US FTC. ${ }^{50}$ Both

\footnotetext{
${ }^{46}$ Id. supra, at paras 196-198.

${ }^{47}$ Id. supra, see eg. para 192.

${ }^{48}$ Id. supra, at para 202.

49 Id. supra, at para 223.

${ }^{50}$ FTC decision Proposed Acquisition of Hellman \& Friedman Capital Partners V, LP, (Click Holding Company) By Google Inc. (20 December 2007), European Commission Case COMP/M.4731 - Google/ DoubleClick (11 March 2008).
} 
authorities analyzed the merger's horizontal and vertical competition risks, reaching broadly similar conclusions. Four points are worth noting on these two investigations.

The first is that both authorities expressly stated that their decision is without prejudice to any data protection and privacy legislation, and also that the relevant data privacy aspects had to be dealt with separately and are not for competition authorities to address. In particular it is worth noting that during the EU investigation, a large number of market participants and civil society groups voiced concerns that the proposed concentration would violate privacy rules. ${ }^{51}$ Such concerns focused in particular on the effects of combining the parties' datasets. As EU officials confirmed in a later paper, the Commission in the case adopted a perspective that took privacy aspects as being distinct from the competition law ones. ${ }^{52}$

The second point to note is that the European Commission in its decision described third party tracking activities in detail, without however calling them a "market" or using the expression "third party tracking", explaining the activities of entities that collect data from third party websites as part of delivering ad serving tools. ${ }^{53}$ Compared to the other European Commission decisions we looked at, in this case the Commission here went into a high level of detail on data collection aspects and the potential that the merger of two databases might have on the merging parties' market position.

The related third point is that both the European Commission and the Federal Trade Commission examined a theory of harm according to which the combination of Google and DoubleClick's databases would give the integrated entity an overwhelming advantage over other competitors. The competitors were understood as being other ad intermediaries by the FTC, ${ }^{54}$ and possibly also entities offering bundled intermediation and ad serving services by the European Commission. ${ }^{55}$ While the European Commission described the data collection aspects in greater detail, both authorities agreed that the merger would not increase the merged entity's power on the relevant market(s), mainly on contractual grounds. In the following passage, the European Commission explained some of the harms at stake, stating that contractual restrictions were in place which could prevent the databases from being merged:

51 Julia BROCKHOFF et al., Google/DoubleClick: The first test for the Commission's non- horizontal merger guidelines, 8 (2008), p. 59, http://ec.europa.eu/competition/publications/cpn/2008 2 53.pdf.

${ }^{52}$ Id. supra. An approach we will call "purist" later in the paper.

${ }^{53}$ See European Commission decision of 22 July 2008 M.4731 Google/Doublelick, at paras. 181-189, 255-267.

${ }^{54}$ According to the FTC, see FTC statement at p. 12 and following: https://www.ftc.gov/system/files/documents/public statements/418081/071220googledccommstmt.pdf

${ }^{55}$ See Commission decision, at. Paras 359 and following. 
"It is not excluded that, from a factual point of view, the merged entity would be able to combine DoubleClick's and Google's data collections. Such a combination, using information about users' IP addresses, cookie IDs and connection times to correctly match records from both databases, could result in individual users' search histories being linked to the same users' past surfing behaviour on the internet. For instance, after such a match, the merged entity may know that the same user has searched for terms $A$, $B$ and $C$ and visited web pages $X, Y$ and $Z$ in the past week. Such information could potentially be used to better target ads to users.

The notifying party submitted that DoubleClick's current contracts with advertisers do not allow the use of data regarding which web pages a user visited, in order to better target ads from other advertisers than those that were instrumental in bringing this data into existence, that is to say, the advertiser that had served an ad to the user when the user was visiting the web page. By extension, the merged entity would also be contractually prevented from using that part of its enlarged database originating from DoubleClick to improve, for example, targeting of search ads on Google's sites or contextual ads in the AdSense network. However, these contracts could be waived, modified or renegotiated." 56

As we can see, reliance on contractual agreements is a weak basis for dismissing competition concerns about increases in market power, ${ }^{57}$ or loss of competitive constraints on a given data-sensitive market.

The final point to note is that two FTC Commissioners issued separate statements, both emphasizing the privacy implications of the merger, and adding interesting comments on the future of merger control in the digital sector. Commissioner Leibowitz commented that privacy issues "clearly transcend" the antitrust issues in this case. ${ }^{58} \mathrm{He}$ argued that:

"rampant tracking of our online conduct, as well as the resulting consumer profiling and targeting, raises critical issues about the sufficiency of companies' disclosures, the depth of consumers' understanding and control of their personal information, and the security and confidentiality of the massive collection of sensitive personal data... In [his]view, the Commission should consider how to address these privacy issues across industries and from multiple perspectives." 59

Adding that "if the online industry does not adequately address consumer privacy through self-regulatory approaches, it may well risk a far greater response from

\footnotetext{
${ }^{56}$ Id. supra. at para. $360-362$.

57 "Market power" is defined as "the ability of one or more firms to profitably increase prices, reduce output, choice or quality of goods and services, diminish innovation, or otherwise influence parameters of competition" in the Horizontal Merger Guidelines (2004/C 31/03), https://eur-lex.europa.eu/legalcontent/EN/ALL/?uri=CELEX\%3A52004XC0205\%2802\%29.

${ }^{58}$ Concurring Statement of Commissioner Leibowitz in the Google/DoubleClick Matter, FTC File No. 071-0170, 20 December 2007.

${ }^{59}$ Id. supra.
} 
government,"60 Commissioner Harbour dissented in the FTC decision because of her belief that the merger could have a far-reaching negative impact on consumers. ${ }^{61}$ She argued that the FTC should have imposed some remedies on the merging parties, using the full scope of its statutory powers under section 5 of the FTC Act, a section that empowers it to act both to protect competition and consumer welfare. Her view was that the FTC relied instead on a traditional understanding of competition, which led it to dismiss the case without privacy safeguards for consumers. On the question of privacy, she noted:

"senior corporate officials have offered assurances that the combined firm will not use consumer data inappropriately. But charged as I am with protecting the interests of consumers, I am uncomfortable accepting the merging parties' nonbinding representations at face value. The truth is, we really do not know what Google/DoubleClick can or will do with its trove of information about consumers' Internet habits. The merger creates a firm with vast knowledge of consumer preferences, subject to very little accountability." 62

The FTC and the European Commission generally take different approaches to competition law enforcement, particularly in non-merger cases. The influence of Chicago School economics on US antitrust authorities' approach has contributed to their tolerance toward large monopolies and conglomerates of power, including those that lead to the centralisation of control over enormous amounts of data. In the EU, instead, it could be argued that protection against monopoly power is a paramount concern. ${ }^{63}$ In particular, abuses by companies of their dominant position on a market is prohibited under Article 102 of the Treaty on the Functioning of the EU. This ideological difference between US and EU competition law enforcement is reflected in the European Commission's arguably bolder competition law stance towards conglomerates of economic power in mergers and unilateral behaviour cases. In this particular instance, however, it seems that the approach of the two authorities was similar and that the FTC procedure allowed its Commissioners to display greater sensitivity toward privacy concerns, albeit mostly in the form of a dissent.

\subsection{Microsoft/Linkedin}

In its Microsoft/Linkedln decision, ${ }^{64}$ the European Commission identified two possible theories of harm resulting from the combination of Microsoft and Linkedln's respective databases. Harm could arise if the datasets increased the merged entity's market power on the market for such data, impeding access to new entrants; or if the two entities were previous competitors on the basis of their

\footnotetext{
60 Id. supra.

${ }^{61}$ Dissenting Statement of Commissioner Harbour In the Matter of Google/DoubleClick, FTC File No. 071-0170, 20 December 2007.

62 Id. supra, at p. 9-10.

${ }^{63}$ For a broader discussion of the US approach towards monopolies in the digital sector, see eg. Maurice Stucke, Should We Be Concerned About Data-opolies? Georgetown Law Technology Review (2018), https://www.georgetownlawtechreview.org/should-webe-concerned-about-data-opolies/GLTR-07-2018/.

${ }^{64}$ European Commission Case COMP/M.8124 - Microsoft / Linkedln (6 December 2016).
} 
data, and stopped competing as a result of the merger. ${ }^{65}$ However according to the Commission the possibility of such harms did not arise in this case for three reasons: first, neither Microsoft nor Linkedln made available their data to third parties for advertising purposes, with very limited exceptions. Second, the market for valuable internet user data available for advertising purposes was so competitive that the combined dataset would not be capable of excluding third parties from the online advertising market. Third, Microsoft and Linkedln were both small players on the online advertising market and competed with each other only to a very limited extent. ${ }^{66}$

The Commission's reasoning here appears too narrow in three respects. First, the assumption that if the parties do not sell data to others there is no "market effect" is flawed: internal use of data by an entity can have a huge impact on consumers, eg. use of data in the creation of profiling or the training of Al models has value even when the data isn't sold. Facebook for instance offers advertisers the highly valued possibility to target ads to specific groups of users that Facebook has preidentified but does not offer these advertisers access to any raw or individualized data about the users. Following the Commission's reasoning, it could be argued that Facebook's use data for advertising purposes does not have a direct market effect on advertisers. This reasoning would be unsustainable. Second, stating that the online advertising market is competitive because players can access a lot of valuable data that is not controlled by Microsoft or Linkedln does not justify the claim that merging the two databases would have no significant impact on consumers: merging data can have implications for consumers because of the increased profiling and behavioral targeting capabilities of the merged entity, even if there is no harm to other competitors. Finally, the Commission in its decision appears to emphasize the fact that parties are contractually prevented from sharing data with third parties, without sufficiently investigating the potential of any future breaches of or amendments to those contracts, or imposing remedies in that regard.

\subsection{Verizon/Yahoo}

The same two theories of harm were discussed by the Commission in its Verizon/Yahoo merger decision, another of the decisions we identified through our methodology: ${ }^{67}$ barriers to entry for competitors as a result of increased market power on the data market; or the two entities were previous competitors on the basis of their data, and stopped competing as a result of the merger. In addition to the grounds provided in Microsoft/Linkedln for why such harms do not arise in this case, the Commission added:

"the vast majority of respondents to the market investigation indicated that the data collected by Yahoo and Verizon cannot be characterised as unique. Similar to other providers of online advertising services, Verizon

\footnotetext{
${ }^{65}$ Id. supra, at para 179.

66 Id. supra, at para 180.

${ }^{67}$ European Commission Case COMP/M.8180 - Verizon / Yahoo (21 December 2016).
} 
and Yahoo are able to capture and utilise data to better target online advertising. One customer noted that it expects the merged entity to be able to improve its data capability which in turn would improve its competitiveness against existing stronger competitors." 68

In other words, the merger would not allow the parties to create unusual or unique profiles, but only profiles that could equally be generated on the basis of existing available data. Even if this were factually true, which would be very difficult to prove, this would not extinguish any anti-competitive or data protection concerns about the merger: the more proprietary data an entity controls, the more it can use it to its advantage on the market. This point was left unaddressed by the European Commission in its decision.

To summarise the conclusions of this section: regulators have overlooked several key aspects involved in consolidation between third party trackers. First, only a small number of the most significant consolidations (in terms of data consolidation) were reviewed at all, and an even smaller number were reviewed in depth. This prompts us to consider whether alternative measures or thresholds are needed to ensure that important data-sensitive mergers are reviewed by regulators. Second, aside from a small number of cases which we shortlisted as delving more deeply into the data issues (Google / Doubleclick, Yahoo/ Verizon, and Microsoft/Linkedln), aspects of third-party tracking that are problematic from a competition standpoint and that have been identified in previous sections seem to have been disregarded or simply missed.

Further, even in those cases where third party aspects were addressed, no investigation of the prevalence, prominence and nature of the first party websites or apps on which each third party tracker was present, appears to have been made. Not to mention the fact that in none of these cases we found "third party tracking" activities described as a relevant market or specific sector of relevant economic activity. The third omission is intentional rather than accidental; regulators have more often than not explicitly ruled out consideration of privacy and data protection aspects of these mergers as outside the scope of competition law. An interesting case study for this kind of trend is the Facebook/Whatsapp merger decision ${ }^{69}$ which, even though it does not tackle issues of third party tracking, illustrates antitrust authorities' reluctance to engage with data protection considerations. ${ }^{70}$ In Google/Doubleclick, Commissioner Harbour's dissenting opinion is the exception that confounds the general trend. Overall, this analysis appears to confirm that competition authorities' approach to mergers in the data

\footnotetext{
68 Id. supra, at para. 93.

${ }^{69}$ European Commission Case COMP M.7217 FACEBOOK/ WHATSAPP, decision of (3 October 2014), http://ec.europa.eu/competition/mergers/cases/decisions/m72172014100320310396 2132 EN.pdf.

${ }^{70}$ Id. supra at paragraph 164: "Any privacy-related concerns flowing from the increased concentration of data within the control of Facebook as a result of the Transaction do not fall within the scope of the EU competition law rules but within the scope of the EU data protection rules."
} 
sector is limited by an excessive focus on economic concerns to the detriment of a holistic analysis of the harms and benefits that may result from these mergers for consumers and society. A pluralist approach which takes the impacts of data collection and use seriously in an analysis of economic and societal effects would be welcome going forward.

\section{Competing views of antitrust law and of the relationship between antitrust and privacy protection}

The reviews mentioned above took place against a backdrop of shifting and conflicting understandings about the relationship between antitrust and privacy aspects of mergers in the digital sector. The importance of both antitrust and privacy aspects is particularly salient when looking at mergers in the third party tracking sector. Mergers and acquisitions between companies that engage in third party tracking can allow companies to increase their market power and their ability to track and profile individuals, to the detriment of consumers and in some cases also of other competitors.

In this section, we articulate some of the current debates underpinning the relationship of antitrust and privacy protection. First, we elaborate on the tension between two 'archetypal' views of the role of competition law going forward: the first view sees competition law as a narrow field and as a purist discipline whose goal is to ensure the efficiency of markets, and the maximisation of a narrow understanding of welfare and competitiveness mostly based on price. The second view sees competition law as one tool in a larger toolbox, which enables the promotion of a variety of economic values and societal goods, and which goes hand-in-hand with data protection and privacy law. After arguing that a pluralist view is more compelling, we move to articulate our theoretical position on the value of data. Our view is that data has both proprietary and personal aspects, and that therefore, while not amounting to an asset that is tradeable and has fixed value, data does have quantifiable market effects which must be assessed by competition authorities.

\subsection{The purist and pluralist views}

\section{The purist view}

We define the purist conception of antitrust as the understanding that antitrust is a pure discipline with rigid boundaries, focused on the promotion of market efficiencies and the limited correction of market failures. The claim that underlies a purist view of antitrust law is that markets are mostly capable of correcting 
themselves and thus that any state or regulatory interferences in markets must be kept to an absolute minimum.

Having first emerged in the 1940s, these so-called "neoclassical" economic ideas were re-adopted in the 1970ies and 80ies under President Reagan in the United States and became very influential in antitrust enforcement circles: quasi blind faith in the efficiency of markets and in the uncoordinated choices of rational profitmaximizing economic actors, the idea that competition is a "self-initiating process" 71 that requires minimal regulatory intervention and that "the proper lens for viewing antitrust problems is price theory."72 In Robert Bork's foundational work The Antitrust Paradox, he asserted that "the only legitimate goal of antitrust is the maximization of consumer welfare," ${ }^{73}$ and that "[i]n judging consumer welfare, productive efficiency, the single most important factor contributing to that welfare, must be given due weight along with allocative efficiency." 74

The tendency to confine the scope of antitrust law to narrow questions of market failure corrections, efficiencies and welfare narrowly conceived is perhaps most prevalent in the US, but can be noticed also in the decisions of European competition authorities. As demonstrated in this paper, the attempt to maintain rigid boundaries for antitrust has indeed led EU and US regulators alike to overlook important concerns and to exercise bad judgment on whether certain data sensitive M\&A transactions should be allowed to go through. Yet finding a unique and uncontroversial objective for antitrust regulation, or coming to a unified view on the meaning of consumer welfare, economic efficiency, economic freedom or an effective competitive process, is practically impossible. Further, the attempt to confine the discipline's scope of application has led to a decline in the relevance of antitrust reviews in recent years. As Maurice Stucke has warned, maintaining a purist approach to antitrust law divorces the discipline from reality and renders it irrelevant and obsolete. ${ }^{75}$

As we saw, competition authorities' reluctance to embrace the non-monetary value of data in the third party tracking industry, their stubborn focus on short term productive efficiencies and neglect of long term distributional implications, their attempt to find a rational basis for distinguishing their role from that of other regulators engaged in a similar enterprise, are all evidence of a failure of competition law enforcement in recent years, and of the merger review process in particular.

\footnotetext{
${ }^{71}$ Unilateral Conduct Working Group, Report on the Objectives of Unilateral Conduct Laws, Assessment of Dominance/Substantial Market Power, and State-Created Monopolies (Moscow: International Competition Network, May 2007), http://www.internationalcompetitionnetwork.org/uploads/library/doc353.pdf.

72 Richard A. Posner, The Chicago School of Antitrust Analysis, 127 University of Pennsylvania Law Review 925, 932 (1978).

${ }^{73}$ Robert H. Bork, The Antitrust Paradox: A Policy at War with Itself (1978), at 7.

${ }^{74} \mathrm{Id}$. supra, at 405.

75 See Maurice Stucke, Reconsidering Antitrust's Goals, 53 Boston College Law Review 551, 611 (2012), https://lawdigitalcommons.bc.edu/bclr/vol53/iss2/4.
} 


\section{The pluralist view}

In light of our analysis so far, it seems that antitrust authorities must thus be ready to embrace greater complexity, and be bolder in analyzing the effects of mergers that have an impact on personal data, instead of hiding such complexities behind the appearance of disciplinary coherence and a misleadingly neutral language.

Reliance on the Chicago School paradigm as the most promising model for disciplinary purity does not appear to have adequately equipped US antitrust authorities to address the needs of the digital economy: the DOJ brought thirtynine civil and three criminal monopolization cases between 1970 and 1972 and only one since $2000 .{ }^{76}$ Further, criticism is mounting against the neoclassical belief that monopolies that maintain low prices or offer free services increase consumer welfare: ${ }^{77}$ if regulators fail to intervene, in the long run predatory pricing eliminates competitors allowing monopolists to charge higher prices and diminish consumer welfare. The focus on short term efficiencies to the detriment of long-term effects is beginning to show its fallacies. The effects of large monopolies that expanded in the absence of early regulatory intervention, may later prove very costly to address.

But the flaws of neoclassical economic thinking are not the only reason to reject a purist perspective on competition law. Orla Lynskey argued that traditional economic understandings of market power based on the ability to charge higher prices, as per the definition of market power in the Horizontal Merger Guidelines, ${ }^{78}$ are too limited. ${ }^{79}$ Economists unsurprisingly disagree on how to measure and understand market power from a purist economic perspective. ${ }^{80}$ Lynskey's suggestion of a broader understanding of platforms' power that accounts for the non-economic values at stake in antitrust investigations that takes the distributional implications of power concentrations seriously is thus to be welcomed.

Reflecting on some of the shortcomings of a purist perspective on mergers and acquisitions, in her dissent in the Google/Doubleclick FTC Commissioner Harbour wrote:

"Traditional competition analysis of Google's acquisition of DoubleClick fails to capture the interests of all the relevant parties. Google and DoubleClick's customers are web-based publishers and advertisers who

\footnotetext{
${ }^{76}$ See Maurice Stucke, Should We Be Concerned About Data-opolies? 2 Georgetown Law Technology Review 275, 280 (2018), https://www.georgetownlawtechreview.org/should-we-be-concerned-about-dataopolies/GLTR-07-2018/.

${ }^{77}$ See Lina Kahn, Amazon's Antitrust Paradox, 126 Yale Law Journal (2017).

${ }^{78}$ EU Horizontal Merger Guidelines at para 8.

79 Orla Lynskey, Regulating "Platform Power," LSE Law, Society and Economy Working Papers (2017), http://www.ssrn.com/abstract=2921021 (last visited Aug 15, 2018).

80 See the case of Streetmap.eu Ltd v Google Inc. \& Ors [2016] EWHC 253 (Ch), at para. 47 , where the judge discusses contrasting economic experts' evidence.
} 
will profit from better-targeted advertising. From the perspective of these customers, the more data the combined firm is able to gather and mine, the better (assuming, as the majority presumably does, that the financial benefits of highly-targeted advertising outweigh any harm caused by reduced competition). But this analysis does not reflect the values of the consumers whose data will be gathered and analyzed. Under the majority's application of Section $7\left[^{81}\right]$, there is no adequate proxy for the consumers whose privacy is at stake, because consumers have no business relationship with Google or DoubleClick."82

Commissioner Harbour's dissenting statement beautifully reflects some of the concerns that we have with the FTC and European Commission's reviews of the merger cases we analysed. Competition law cannot exclude the human and social impacts of data mergers from its scope of analysis. We must thus start thinking across and beyond competition and data protection's disciplinary boundaries, looking for solutions to the dynamically evolving digital sector.

\subsection{The value of data}

Data can be valued in different ways and for different purposes. Claims over data indeed can be understood in at least two distinct ways: (a) as claims based on proprietary or economic interests over data as an asset, including intellectual property rights or rights to use the data as part of an economic activity, ${ }^{83}$ or (b) as claims based on personal human interests in data or dataflows as related to the shaping of one's own person and personal image in the eyes of others. ${ }^{84}$ Both types of claims over data can exist simultaneously: a content sharing platform might have an economic interest in maintaining list of user names, their sex and their content preferences in order to better target ads at them and generate a profit; a user, on the other hand, might have a personal interest in the information that the platform holds about her. The platform or the community at large might also have other non-economic interests in the data: for instance, maintaining such a record of users or individuals can be said to improve user-experience or lead to other societal gains that are independent of whether it allows the platform to generate a profit. To complicate the matter further, while an individual platform user may have personal interests over the data, other non-users of the platform might also have personal interests in that same data or data that has been opaquely linked to it. These various types of interests over data sometimes go hand in hand, and other times do not: for example when a user does not want the platform to hold information about them and use it for commercial purposes, or

\footnotetext{
${ }^{81}$ Section 7 of the United States Clayton Act prohibits mergers and acquisitions where the effect "may be substantially to lessen competition, or to tend to create a monopoly." 82 Dissenting Statement of Commissioner Harbour In the Matter of Google/DoubleClick, FTC File No. 071-0170, 20 December 2007, at p. 10.

${ }^{83}$ E.g. see Jeffrey Ritter; Anna Mayer, Regulating Data as Property: A New Construct for Moving Forward, 16 Duke L \& Technology Rev 220 (2018).

${ }^{84}$ See eg. Mireille Hildebrandt, Smart technologies and the Ends of Law (2015); Helen Nissenbaum, Privacy in Context (2010); Julie E. Cohen, Configuring the Networked Self (2012).
} 
when a user accept the platform's practices but a non-user is indirectly also affected by the practice and cannot object.

When it comes to the assessment of mergers in the third party tracking industry, it seems that considering data's value as altogether an economic asset and as an individual or collective good complicates competition authorities' task. Should they be bold and consider any effects of data in economic terms as having a market effect? Should they instead refrain from considering these questions altogether and defer matters to data protection or privacy regulators?

While acknowledging the difficulties in addressing this question, our view is that it would be wrong for competition authorities to consider data as a pure economic asset and to subsume data matters within routine competition law analysis. Data are not assets that can be uncontroversially, let alone easily, be quantified in monetary terms. As Cass Sunstein has recently shown, the value that we attach to digital goods is highly contextual and subject to variations that are not explainable in mainstream economic terms. ${ }^{85}$ On the other hand, we believe that a pluralist perspective on the role of competition law enforcement would allow competition authorities to construe questions of "market effect" or "market power" broadly enough to encompass the analysis of direct and indirect harms resulting from the creation of large concentrations of power and control over data. Considering data as being more like money, as some economists would be tempted to suggest, does not in our view solve the current problems that underlie mergers and acquisitions in the third party tracking industry. What would address the problem, is a bolder, more informed, consideration of the harms at stake, and of how individuals, be they users or third parties, are affected.

\section{Competition and data protection: some conclusions}

Commissioner Harbour's dissenting position over Google / DoubleClick has proved prescient. In the years since the acquisition, the Alphabet companies (including Google and Doubleclick) have expanded the reach of their third party tracking capability to encompass the majority of all websites and apps on the Android platform. ${ }^{86}$ As section 2 attests, recent years have seen numerous significant consolidations amongst other firms which engage in third party tracking. The third party tracking aspects of these mergers and acquisitions raise additional complications which have not been reflected in the existing discussion about the relationship between data accumulation, competition, and data protection.

\footnotetext{
${ }^{85}$ Cass Sunstein, Valuing Facebook, Behavioural Public Policy, Forthcoming (2018), available in draft at: https://papers.ssrn.com/sol3/papers.cfm?abstract_id=3241348. ${ }^{86}$ The reach of these entities on the Apple iOS platform is unknown, due to the Apple distribution and security model making large scale empirical research impractical.
} 
The way these issues will be addressed in future depends on evolving institutional views about the relationship between competition and data protection. The analysis above points to several shortcomings of existing approaches, and suggests the need for certain new elements that ought to form part of these respective regulators' approaches in future.

Traditional thresholds for review may need supplementing with new measures: the current approach is one in which reviews are triggered by market share and turnover thresholds, not thresholds accounting for power and control over data. This leads authorities to fail to review certain mergers which might be highly significant in terms of the data combined, even if one or both firms do not have a significant market share or significant revenue measured in monetary terms. Under the current turnover and market share-based tests, large datamergers are often missed. Competition authorities' merger reviews take no account of the number first party sites that the third party tracker is present on, nor of the popularity of such first parties. In other words, competition authorities are not required to know how significant or prevalent a given third party tracker's activities are on the web or on mobile. This in our view needs to change in future.

Data protection and competition might sometimes pull in opposite directions regarding third party tracking. In spite of embracing a pluralist view of antitrust regulation and considering that better competition law enforcement and greater privacy protection generally go hand in hand, we recognize that privacy and competition law may sometimes appear to conflict.

Consolidation between third party trackers could be both positive and negative for privacy. On the one hand, the more websites or applications that a particular thirdparty tracker is integrated with, the more comprehensive and revealing the profiles it can build, and the fewer first party options an individual has if they wish to avoid the third party. On the other hand, if a new third party enters the market, assuming first parties integrate it without substituting any existing third parties, this can increase the number of trackers that users of those first parties are exposed to, whilst also reducing market concentration. There may therefore be a trade-off in some cases between reducing the overall number of tracking firms to which an average individual is exposed, and reducing the amount of different data types that any one tracker can amass about a given consumer.

Because of the nature of third party tracking technology and business models, forms of market activity that are acceptable or even positive from a competition law perspective may thus at times fall short of desirability from a data protection perspective. When this occurs, it is important for competition and data protection authorities to engage in a collaborative dialogue. The starting point for such dialogue, we maintain, must be the values to be protected and the harms to be avoided, not disputes around disciplinary boundaries and exclusive competencies.

The nature of data combination is more complicated to ascertain in the case of third party mergers: Consolidations between firms who collect their data directly from users - such as Facebook and Whatsapp - are easier to scrutinise 
because the first party data is limited and known. But firms who operate third party tracking networks collect their data indirectly via first parties, and it may therefore be difficult to know exactly the volume and variety of data being combined as a result of mergers between them. This perhaps explains why in the decisions that we analysed competition authorities focus on the first-party rather than third-party data collection by those firms.

But a merger between third party trackers does not just affect users of two services, it affects all users of all the multiple different services on which each tracker is present pre-merger. In many cases, third party trackers may not even be able to fully audit which sites or apps they are present on, because they provide open APIs which are used by first parties. Thus, even if authorities have on some occasions considered the effects of merging different data sources, they have generally failed to do this thoroughly, even in significant cases like Verizon / Yahoo. A full audit of all first party data sources, and the effects of combining them, would indeed be a significant undertaking, because of the sheer number and variety of combinations. But without it, it is difficult to see how an appropriate judgement could be made as to the risks involved in combining the two datasets, both to the structure of market competition and the privacy of individuals affected.

Timing and regulation: mergers in the digital sector are characterised by dynamic markets, transient products, changing data and evolving needs. Against this background, the challenge for regulators across the competition and data protection spectrum is to minimize unnecessary and time-consuming burdens while ensuring effective regulation. While this balance is very difficult to strike, if an investigation is complex and time-consuming it is important that regulators consider timeliness and long-term effects. A long investigation that focuses on short term costs and benefits has a high likelihood of leading to costly, misguided results.

Maintaining a static division between purist visions of competition law and data protection risks rendering both irrelevant. A discipline or regulatory authority becomes obsolete if it stops addressing needs of societal importance. Accordingly, antitrust and data protection regulators' concern to stick to the foundations of their disciplines may at times lead them down a rabbit hole, and prevent them from tackling important issues in evolving digital markets. As we have seen, competition regulators often fail to address important issues in third party tracking because of their focus on economic notions of "market effect" "market share" "turnover" "consumer welfare" "efficiency" and so on. Similarly, data protection regulators often overlook important $M \& A$ issues as a result of their lack of familiarity with merger issues. For example, the fact that two companies have complied with their data protection obligations does not mean that an entity resulting from their merger will also automatically be compliant with data protection. Each transaction or data transfer should trigger new notification obligations and a separate scrutiny. 